\title{
¿ES POSIBLE INTERPRETAR LA LEY PENAL INCORPORANDO ANTECEDENTES CRIMINOLÓGICOS?
}

\author{
UNA REVISIÓN DE LAS RELACIONES EPISTEMOLÓGICAS \\ ENTRE AMBAS DISCIPLINAS.
}

ROCÍO SÁNCHEZ PÉREZ*

\section{Resumen}

Desde la obra de Von Liszt el estatuto epistemológico de las ciencias que estudian la cuestión penal ha quedado caracterizado por la relación existente entre Criminología, Dogmática penal y Política Criminal. Esta relación en ciertas ocasiones ha generado conflictos, pero también diálogo interdisciplinar. Considerando el paso del tiempo el siguiente trabajo revisa las vinculaciones actuales y propone una nueva que defiende que la Criminología contribuye a la interpretación de la ley penal.

\section{Palabras Clave}

Criminología; dogmática penal; interpretación de la ley.

\begin{abstract}
Since Von Liszt's work the epistemological status of the sciences that study the criminal question has been characterized by the relationship between Criminology, Criminal Law Theory and Criminal Policy. This relationship has been sometimes conflictive but there has also been

Artículo recibido para su evaluación el 25 de noviembre de 2021, y aprobado para su publicación el 17 de diciembre de 2021.

* Profesora de Derecho Penal, Escuela de Derecho, Universidad Andrés Bello, Viña del Mar. Email: rocio.sanchez@unab.cl
\end{abstract}


interdisciplinary dialogue. With the passage of time and the more complex work of the criminal law interpreters, this work reviews current interactions among these disciplines and proposes a new constructive relationship in which criminology assists the interpretation of criminal law.

\section{Keywords}

Criminology; criminal law; theory an criminal Policy; interpretation of criminal law.

\section{CONSIDERACIONES PRELIMINARES.}

Tradicionalmente se ha señalado que existe una vinculación entre la Criminología y el Derecho penal. Su origen se funda en la propuesta de la Enciclopedia criminal desarrollada a partir del trabajo de Von Liszt, que tuvo como antecedente el concepto de Ciencia integral del Derecho penal propuesto por la Asociación Internacional de Criminalística y su programa. ${ }^{1}$

Dicha obra contribuyó a establecer un estatuto epistemológico para el Derecho penal, la Criminología y la Política Criminal, vigente hasta nuestros días. Desde ahí en adelante la investigación criminológica se enfocó en estudiar las causas del delito y los efectos de las penas. En el plano teórico, ese material es suministro indispensable para diseñar la Política Criminal; concretamente, las decisiones legislativas se tomarán a partir del conocimiento científico recaído en las causas del delito, ${ }^{2}$ que luego se expresará en el Derecho penal. ${ }^{3}$

Partiendo de la propuesta desarrollada por Von Liszt, recogida y modificada por innumerables especialistas, se cuestionará si es posible detectar nuevas conexiones metodológicas entre Criminología y dogmática penal, como actividad dedicada al Derecho penal, procurando no

1 VORMBAUM, Thomas: Historia moderna del Derecho penal alemán, Tirant lo Blanch, Valencia, (traducción de Carlos Elbert), 2018. p. 21.

2 DÍEZ RIPOLLÉS, José Luis: "El papel epistémico de la política criminal en las ciencias penales: la contribución de v. Liszt”. En: Revista electrónica de Ciencia penal y Criminología, número 20, 2018. p. 16.

3 La obra de Von Liszt dio un impulso definitivo al conocimiento penal, por lo que "desde entonces, el saber penal ha retornado a la situación precedente”. En ese sentido: DÍEZ, RIPOLLÉS, José Luis, op. cit., p. 31. 
desnaturalizar ambas disciplinas, manteniendo los métodos de cada una y los compartimentos epistemológicos antes descritos.

En ese sentido, la hipótesis planteada en esta investigación es que la interpretación de la ley penal permite conectar el trabajo de la ciencia jurídico-penal con la información sobre el fenómeno criminal aportada por la Criminología, siendo esta un área no explorada profundamente en el desarrollo teórico.

Si bien usualmente se reconoce el valor que los estudios criminológicos tienen en el desarrollo de la política criminal, es decir, en un momento anterior a la dictación de la ley penal, no se ha explorado lo suficiente su aporte metodológico a posteriori, es decir, una vez configurado el texto de la ley punitiva en los problemas de determinación de su significado.

Para materializar esa idea, es necesario analizar algunos aspectos derivados del estatuto epistemológico de ambas disciplinas. Ello se traduce en diversas preguntas, una de las cuales supone reflexionar, en general, acerca del carácter científico del trabajo de la dogmática jurídico-penal, lo que también se puede extender al campo criminológico. Todas estas dudas conducen a analizar la relación entre ambas disciplinas.

Con ello, se pretende describir más claramente ambos estatutos epistemológicos, teniendo en consideración la posible incorporación de información criminológica en el proceso de atribución de significado de las leyes penales. Como ha señalado recientemente Perin "se defiende la necesidad de "no inmunizar" el pensamiento jurídico de la evolución del debate epistemológico contemporáneo". ${ }^{4} \mathrm{Al}$ fin y al cabo, si estamos analizando relaciones entre ciencias, es relevante conocer su ubicación en el panorama general y la forma en que procesan los antecedentes que provienen desde otras áreas del conocimiento.

\section{REVISIÓN DE ALGUNOS ASPECTOS EPISTEMOLÓGICOS RELEVANTES EN LA CIENCIA JURÍDICO-PENAL.}

En el seno de la dogmática jurídico-penal se ha discutido extensamente sobre diversos aspectos metodológicos, incluyendo la cientificidad de su trabajo y conclusiones. La lucha de las Escuelas permite visualizar

4 PERIN, Andrea: "Conocimientos científicos, tecnologías convergentes y Derecho penal. Reflexiones metodológicas en materia de causalidad, imprudencia, imputabilidad y peligrosidad”. En: Tecnologías convergentes: desafios éticos y jurídicos, Comares, Granada, 2016. p. 152. 
propuestas teóricas heterogéneas. Si nos remontamos a los aportes de Von Liszt distinguiremos el carácter científico de la dogmática penal y procesal penal, cumpliendo una función y aplicando un método distinto que las otras disciplinas que componen la enciclopedia de disciplinas criminales. ${ }^{5}$

A lo largo de los años los paradigmas cambiaron y ello repercutió en la construcción teórica más relevante de la disciplina punitiva, la teoría del delito. Tal como recuerda Schurmann, a partir del tránsito de teorías causalistas, finalistas y funcionalistas, "es posible observar períodos de coexistencia de programas de investigación, entre la emergencia y la obsolescencia de ellos. Al contrario, en todos los casos el cambio teórico ha sido calificado como racional, dado que la teoría sucesora tuvo un mayor poder explicativo y heurístico que la antecesora, en los términos previstos por Lakatos". ${ }^{6}$

En nuestros días, un amplio sector de la doctrina penal asume que su trabajo es científico. Zaffaroni comparte esta idea en la medida que el jurista emplea el método jurídico, consistente en analizar, interpretar y comprender textos legales, ${ }^{7}$ encaminado a contener y restringir las pulsiones del poder punitivo. ${ }^{8}$ También, desde una perspectiva garantista, Silva Sánchez entiende que la dogmática jurídico-penal constituye la ciencia jurídico-penal por excelencia, ${ }^{9} \sin$ perjuicio de reconocer expresamente las complejidades existentes para delimitar qué se entiende por ellas. ${ }^{10}$ Por el

5 DÍEZ RIPOLLÉS, José Luis, op cit., p. 16.

6 SCHURMANN OPAZO, Miguel: “¿Es científico el discurso elaborado por la dogmática jurídica? Una defensa de la pretención de racionalidad del discurso dogmático elaborado por la ciencia del derecho penal”. En: Política Criminal, volumen 14, número 27, 2019. p. 591.

7 ZAFFARONI, Raúl E: Manual de Derecho penal. Parte general, Ediar, Buenos Aires, 2012. p. 69.

8 Ibídem, p. 76.

9 SILVA SÁNCHEZ, Jesús María: Aproximación al Derecho penal Contemporáneo, Editorial B de F, Buenos Aires, 2010. p. 66.

10 En Italia, Donini reconoce la vigencia de un modelo integrado por ciencias hermenéuticas y empíricas. DONINI, Massimo: "Democrazia e scienza penale nell'Italia di oggi: un rapporto possibile". En: Rivista italiana di diritto e procedura penale, volumen 53, número 3, 2010. p. 1079. En Alemania, Jakobs entiende que realmente estamos frente a una ciencia. JAKOBS, Günter: El Derecho penal como disciplina cientifica, Thomson, civitas, Pamplona, (traducción de Alex van Weezel), 2008. p. 22. También Kindhäuser la describe como una ciencia de la justicia con vocación práctica: KINDHÄUSER, Urs: "Acerca del objeto y la tarea de la ciencia del Derecho penal". En: Derecho penal contemporáneo. Revista internacional, número 66, 2019. p. 16. 
contrario, voces minoritarias afirman que estamos frente a un proyecto de ciencia, pues metodológicamente adolece de defectos graves. ${ }^{11}$

Este problema puede abordarse desde la perspectiva de aquellos autores que defienden un modelo integral, propiciando una ampliación del modelo vigente tradicionalmente en la dogmática penal, abierto a la incorporación de los aportes de otras disciplinas, como son otras ramas del derecho, pero también hacia otras ciencias sociales como la Criminología, Sociología, Estadística, incluso ciencias empíricas. ${ }^{12}$

Por lo tanto, estaríamos frente a una disciplina que estudia la realidad normativa y social. ${ }^{13}$ La limitación racional a este tipo de trabajos argumentativos reside en el apego a soluciones estrictamente normativas, aplicando las reglas o describiendo su contenido.

Otra forma de solucionar el problema la propuso Kindhäuser, explicando que la ciencia jurídica tiene como objeto un sector del ordenamiento jurídico, pero no es una disciplina homogénea. En realidad, bajo su amparo se desarrollan actividades intelectuales distintas, que siguen diferentes caminos metodológicos y asumen diversos paradigmas epistemológicos, lo que conduce a una confusión de teorías complejas. ${ }^{14}$

En primer lugar, la dogmática o ciencia penal en sentido estricto, desarrolla las condiciones para la aplicación del derecho punitivo vigente. ${ }^{15}$ Para ello, aplica un método racional y sistemático. Mediante la interpretación intenta aclarar el contenido de las reglas jurídico-penales. Además, elabora

11 Se ha reconocido que esta disciplina tiene dificultades profundas para encaminar y armonizar el estudio de eventos empíricos con requisitos subjetivos. Sumado a los problemas para imponer categorías normativas de forma independiente a las conclusiones de las ciencias básicas. También cuestiona el carácter científico, pues no portaría un mínimo ético, lo que permite discutir sobre sus modelos, herramientas y reglas de intervención. Finalmente, descarta que se trate de una ciencia social, pues no pretende conocer las dinámicas sociales respecto del crimen. En este sentido: EUSEBI, Luciano: La pena "in castigo". Vita e Pensiero, Milano, 2006. pp. 38 y 39.

12 Dichos planteamientos se basan en una forma especial de comprender al derecho, que no se reduce solamente a normas, sino que abarca las decisiones judiciales y la dimensión institucional de los creadores y aplicadores del sistema jurídico. También han extendido el posible contenido de la norma jurídico penal, a partir de la incorporación de los intereses protegidos y la realidad política, económica, criminológica, entre otras. Además, incluyen la dimensión social de la criminalidad, que podrá ser comprendida según la información suministradas por otros saberes no normativos.

13 DONINI, Massimo, op. cit., 2010, p. 1078.

14 KINDHÄUSER, Urs, op. cit., p. 19.

15 Ibídem, p. 19. 
una red conceptual en el propio derecho punitivo y armoniza las relaciones con las estructuras de otras áreas jurídicas. ${ }^{16}$

En este nivel se puede agregar la propuesta racionalizadora de Hruschka, ya que la dogmática penal busca posibilitar el proceso de configuración de la legislación criminal y la aplicación de la jurisprudencia, mediante análisis comprensivos de sistemas complejos de casos. ${ }^{17}$

En segundo lugar, la teoría jurídica desarrolla una labor meta-dogmática, sustentada en la teoría de la ciencia y la impulsada en el campo jurídico. Concretamente "se dedica a revisar las interacciones entre las distintas reglas que componen el derecho punitivo". ${ }^{18}$

Seguidamente, distingue al empirismo (o investigación empírica de hechos jurídicos), como una dimensión de la ciencia jurídica que busca asegurar que el derecho se ajuste a los hechos naturales y sociales. Por lo tanto, "la adecuada comprensión de la realidad empíricamente cognoscible es un presupuesto necesario de la adecuada constitución de hechos jurídicos. ${ }^{19}$

En cuarto lugar, reconoce la existencia de la investigación básica sustancial, de carácter filosófico, que estudia los paradigmas y conceptos esenciales de las teorías propuestas. ${ }^{20}$

En términos estrictos, las dos primeras, analizadas autónomamente, constituyen tópicos, en el sentido planteado por Viehweg. De modo que, para alcanzar el carácter científico en términos profundos, es necesario desarrollar una investigación empírica de hechos jurídicos y los estudios básicos sustanciales.

Es interesante el planteamiento de Kindhäuser, pues, dependiendo del sector de trabajo de la ciencia jurídico-penal, encontraremos una mayor recepción a la información aportada por otras disciplinas. Pero además, esa apertura epistemológica repercute en la configuración del resto de los niveles; por ejemplo, una recepción adecuada de los antecedentes fácticos para la construcción del contenido de los conceptos jurídicos -es decir, ciencia en el tercer continente- repercutirá en el trabajo que desarrolle la dogmática penal propiamente tal, al permitir el ejercicio del proceso de

16 Ibídem, pp. 34 y 35.

17 HRUSCHKA, Joachim: Imputación y Derecho penal, segunda edición. Buenos Aires (al cuidado de Pablo Sánchez Ostiz), 2009. p. 367.

18 KINDHÄUSER, Urs, op. cit., 2019, p. 40.

19 Ibíd., p. 40.

20 Ibíd., p. 20. 
autocomprensión normativa, que termina definiendo cuál es el contenido del derecho criminal vigente, pero también en el campo de la filosofía o investigación básica, ya que integrará los paradigmas filosóficos que permiten comprender el fundamento hondo de la institución. ${ }^{21}$

Finalmente, estas últimas propuestas contribuyen a sostener que la dogmática jurídico-penal realiza una labor científica, estudiando el derecho punitivo, pero de forma heterogénea. En algunos sentidos sus aportes serán indudablemente científicos, en cuanto se refieren a métodos y resultados que superan el contenido contingente de los textos jurídicos, profundizando en sus paradigmas y fundamentos. ${ }^{22}$

\section{PRINCIPALES DISCUSIONES EPISTEMOLÓGICAS EN LA CRIMINOLOGÍA.}

Un análisis de los problemas epistemológicos centrales de la Criminología representa una empresa tan compleja como revisar los nudos conflictivos de la ciencia jurídico-penal.

En primer lugar, existe consenso en que no hay un único concepto que la describa. ${ }^{23}$ Además, se trata de una ciencia en constante crecimiento y expansión, que funciona de forma dinámica en diversas latitudes del

21 La propuesta anterior encuentra un punto de contacto con el trabajo de Jakobs, en especial a propósito de la determinación del Derecho legítimo y vigente como tarea de la Ciencia penal (2008: p. 21). Con otras palabras, hablaremos de ciencia si sus estudios precisan qué discurso es la verdadera expresión de la constitución normativa de la sociedad. Para ello debe desarrollar un proceso de autocomprensión normativa en un determinado tiempo y lugar, persiguiendo los cimientos que la legitiman. JAKOBS, Günter, op. cit., p. 22.

22 Tampoco se debe desconocer que los estudios que normalmente se reconocen como dogmáticos, referidos a tareas de interpretación y sistematización interna y externa, son un paso fundamental para alcanzar el estatus ya referido, en la medida que se encaminan por un método argumentativo racional, apegado a la legislación vigente.

23 NEWBURN, Tim: Criminology, tercera edición. Routledge, New York, 2017. p. 5. Algunos especialistas han optado por proponer un concepto amplio, asumiendo que abordan los estudios académicos sobre el crimen y la sanción punitiva. En ese sentido: JIMÉNEZ DE ASÚA, Luis: Tratado de Derecho penal, Tomo I, Editorial Losada, Buenos Aires ,1964. p. 102. Desde una perspectiva más restringida se la ha definido como una "ciencia empírica e interdisciplinaria, que se ocupa del estudio del crimen, de la persona del infractor, la víctima y el control social del comportamiento delictivo. En el fondo, trata de suministrar una información válida y contrastada, sobre la génesis, dinámica y variables principales de la delincuencia -contemplada como problema individual y social-, así como sobre los programas de intervención eficaz del mismo, las técnicas de intervención positiva en el hombre delincuente y los diversos métodos o sistemas de respuesta al delito". En este sentido: GARCÍA PABLOS DE MOLINA, Antonio: Criminología, una introducción a sus fundamentos teóricos. Lexis Nexis, Santiago, 2008. p. 1. 
mundo. ${ }^{24}$ Como si fuera poco, tiene raíces históricas heterogéneas y sus autores han asumido diversos paradigmas..$^{25}$ A ello se suma el debate sobre sus objetos de estudio, y que en su seno conviven disciplinas diferentes, generando límites epistemológicos un poco difusos. ${ }^{26}$

Desde antaño que se cuestiona que realmente sea ciencia ${ }^{27} \mathrm{y}$ en nuestros días algunos afirman que aún no madura. En particular, tratándose de la reducción de la delincuencia se sostuvo que "no estamos seguros de cómo reducir sistemáticamente la gravedad del delito. Tenemos algunas ideas y estamos progresando, pero todavía no hemos llegado". ${ }^{28}$ En respuesta a esas críticas se ha afirmado que la Criminología es una disciplina más joven que las ciencias naturales, con diversas limitaciones, sumado a que la excesiva confianza en las disciplinas naturales representa una exageración.

Sin perjuicio de estos cuestionamientos existe un grado de consenso en que la Criminología entrega información relevante sobre el problema criminal. Más precisamente, brinda antecedentes válidos, fiables y contrastados, pues son obtenidos por aplicación del método científico. ${ }^{29}$

Respecto del objeto de estudio, Agüero desarrolla un resumen especialmente claro del tratamiento que se le ha dado en numerosos manuales relevantes. En concreto, distingue un grupo de autores que fijan "el delito o crimen, el delincuente o infractor, la víctima, y el proceso de criminalización o control social". Otros especialistas centran sus investigaciones en: el crimen, el delincuente y el sistema penal o de control del delito. Un tercer grupo, sostiene que el saber criminológico se sustenta en dos pilares: el comportamiento delictivo y la reacción social a dichos comportamientos, para unos, y el delito y el delincuente como fenómenos sociales para otros. Finalmente, ciertos criminólogos se centran en el delito

24 BOSWORTH, Mary, HOYLE, Carolyn: "What is Criminology? an Introduction". En: What is Criminology, First Edition, Oxford University Press, Oxford, 2011. p. 1.

25 NEWBURN, Tim, op. cit., p. 5.

26 Ibídem., p. 4.

27 SUTHERLAND, Edwin: Principles of Criminology. The United States Armed Forced Institute, Madison, 1939. p. 23.

28 ESKRIDGE, Chris: "El estado actual de la Criminología”. En: Revista Archivos de Criminología, Criminalística y Seguridad Privada, año 6, volumen XI, pp. 415-432, 2013. p. 9.

29 Hoy en día, fruto de la crisis del concepto de causa, esta disciplina no proporciona una respuesta única, basada exclusivamente en un factor para explicar el fenómeno criminal y sus características; sin embargo, sus aportes, en conjunto, deben ser considerados si se pretende comprender la delincuencia y trabajar seriamente en su prevención y sanción. 
o crimen, entendido como un fenómeno omnicomprensivo de casi todas las materias recién enunciadas. ${ }^{30}$

En el medio anglosajón, se sintetiza el objeto de estudio de la siguiente forma: la Criminología describe, mira, explora y debate sobre qué es un delito, cómo se le considera, la oportunidad en que se comete, sus registros e informes, tipos de delitos cometidos o registrados. ${ }^{31}$

En pocas palabras, todas estas propuestas pueden reconducirse al estudio del fenómeno delictivo y la pena, como su reacción social. Es conveniente mencionarlo ya que la Criminología dedicada a las causas del delito, con el paso de los años fue complementada con los aportes de la Criminología crítica que, "al estudiar al delito en un contexto histórico, social y económico", enfatizó la necesidad de examinar el proceso de criminalización. ${ }^{32}$ Así, contribuyó a ampliar notablemente el objeto de estudio, las perspectivas de análisis y los métodos de trabajos a campos nuevos, como son: la Criminología verde, la Criminología cultural, la Criminología de las personas condenadas y la Criminología feminista.

En cuanto al método de trabajo es usual afirmar que se trata de una ciencia que estudia una dimensión de la realidad social, especialmente el crimen. En específico, desarrolla definiciones, explicaciones y respuestas al dicho fenómeno. ${ }^{33} \mathrm{El}$ proceso de generación del conocimiento sobre la delincuencia no es simple, pues esta disciplina tiene varias peculiaridades que requieren ser atendidas. ${ }^{34}$

Hoy existe algún grado de consenso en aceptar que la Criminología es una ciencia del ser, ${ }^{35}$ y que se trata de una ciencia social que estudia la

30 AGÜERO SAN JUAN, Sebastián: "Apuntes sobre las dificultades en la determinación del estatus científico de la Criminología”. En: Revista Chilena de Derecho y Ciencia Política, Volumen 2, número 1, año 1, 2010. p. 52.

31 CASE, Steve, JOHNSON, Phil, MANLOW, David, SMITH, Roger, WILLIAMS, Kate: Criminology, Oxford University Press, Oxford, 2017, p. 32.

32 CID, José, LARRAURI, Elena: Teorias criminológicas, Explicación y prevención de la delincuencia. Bosch, Barcelona, 2001. pp. 241-243.

33 Ibídem, pp. 31-32.

34 El paradigma que influyó fuertemente la investigación criminológica fue el positivista, que a su vez fue fruto de la corriente del pensamiento que propuso aplicar el estudio del comportamiento humano a través del método científico. En ese sentido: SERRANO MAÍLLO, Alfonso: Introducción a la Criminología. UNED, Madrid, 2009. p. 39.

35 GARCÍA PABLOS, Antonio, op. cit., p. 3. 
realidad. ${ }^{36}$ En su esfuerzo por aplicar el método científico sus estudios se fundan en la observación y, en ciertos casos, en la experimentación. ${ }^{37}$

Ahora bien, tratándose de una ciencia social, realiza un análisis empírico, empleando una metodología que permite contrastar, verificar y falsear sus resultados ${ }^{38}$ estableciendo hipótesis, explicaciones y predicciones. Por lo tanto, emplea un método similar al de otras ciencias sociales y naturales, como el sociológico, biológico y el psicológico. ${ }^{39}$ En definitiva, estos trabajos aplican un procedimiento regular, explícito y repetible. ${ }^{40}$

Otro aspecto conflictivo ha sido la decisión metodológica sobre realizar estudios de carácter cuantitativo o cualitativo. En particular los métodos para acceder al conocimiento han ido variando en cada época y lugar, de acuerdo con diversos paradigmas o modelos imperantes ${ }^{41}$ por ejemplo, durante la década del cincuenta predominaron los análisis cuantitativos, pero entrando en la década de los setenta, se desarrollaron más investigaciones cualitativas. ${ }^{42}$ En la época contemporánea, se ha llegado a una especie de consenso que permite emplear ambos tipos de métodos en las investigaciones.

En consecuencia, los estudios cualitativos se aplican a áreas especialmente sensibles, como son los análisis sobre víctimas de delitos sexuales, mientras que las investigaciones cuantitativas suelen utilizarse en otras materias, ${ }^{43}$ pues contribuyen de mejor forma a la comprensión del fenómeno. ${ }^{44}$ Obviamente se admite la combinación de ambos para enriquecer las conclusiones en las investigaciones.

36 JONES, Stephen: Criminology. Oxford University Press, Oxford, 2009. p. 10.

37 SERRANO MAILLO, Alfonso, ob. cit., págs. 39-41.

38 LARRAURI, Elena: Introducción al sistema penal, Trotta, Madrid, 2015, p. 33.

39 GARRIDO GENOVÉS, Vicente y REDONDO ILLESCAS, Santiago: Principios de Criminología, Tirant lo Blanch, Valencia, 2013, p. 130.

40 No debemos olvidar que, en estos estudios, igualmente, se consideran datos secundarios que no son empíricos. En ese sentido: CASE, Steve, op. cit., 2017, p. 140.

41 JONES, Stephen, op. cit., p. 10.

42 Con la irrupción de la Criminología crítica y el cuestionamiento profundo al método de trabajo tradicional, se asumió que la criminalidad no es solamente un fenómeno ontológico de comportamientos y de individuos determinados. Por el contrario, se destacó la existencia de un estado asignado para ciertos grupos de personas seleccionadas. A partir de ello surge la necesidad de que la Criminología cuestione al sistema penal. En ese sentido: BARATTA, Alessandro: Introduzione alla Sociologia giuridico-penale. Criminologia critica e critica al diritto penale, Dispense del ciclo di lezioni tenute alla facoltà di Giurisprudenza dell’Università di Bologna, Bologna 1980. p. 161.

43 JONES, Stephen, op. cit., p. 10

44 CID, José, LARRAURI, Elena, op. cit., p. 243. 
Además, dentro de la gama de estudios desarrollados, se distinguen análisis basados en métodos transversales, que solamente recogen información del fenómeno o variable en un momento preciso, por ejemplo, las estadísticas. También han tenido lugar las investigaciones longitudinales, más complejas metodológica y económicamente hablando, pues obtienen los datos a partir de distintos momentos. Ellas explicarían de mejor forma las dinámicas del fenómeno estudiado, como son los estudios de seguimiento (folow up), las biografías criminales y los case studies. ${ }^{45}$

También las investigaciones pueden clasificarse según los niveles de análisis, como teorías micro o macro. Los primeros estudian aspectos referidos a la persona del autor a nivel individual. Mientras que las denominadas teorías macro analizan estructuras o el sistema social. ${ }^{46}$

Otro aspecto complejo discutido, derivado de que la Criminología es una ciencia social, dice relación con la antigua convicción de que buscaba hallar la causa de los delitos. Dichos cuestionamientos contribuyeron a concluir que es imposible asumir un concepto teórico de causa aplicable a todas las preguntas que analiza la Criminología. Ello derivó en que los criminólogos hicieran lo que Mannheim calificó como una "renuncia teórica" a usar esa noción. ${ }^{47}$ En el fondo, abdicaron de aplicar una causalidad lineal al estudio del fenómeno criminal y sus diversos ámbitos. ${ }^{48}$ En consecuencia, estas investigaciones no aspiran conseguir conclusiones exactas, asumiendo que su propio conocimiento será más "relativo, provisional, abierto e inacabado". 49

En vista de esta abdicación se han adoptado diversas posturas metodológicas para sustentar la investigación criminológica. En primer lugar, se ha propiciado el desarrollo de una teoría ecléctica multicausal. ${ }^{50}$ Expresión de lo anterior son las denominadas teorías integradas, que reconocen las limitaciones de las teorías unitarias y "seleccionan diversos enfoques disciplinarios, variables y teorías criminológicas". ${ }^{51}$ En segundo término, se han abierto espacios a trabajar con nociones como la

45 GARCÍA PABLOS, Antonio, op. cit., p. 10.

46 SERRANO MAÍLLO, Alfonso, op. cit., págs. 206-207.

47 MANNHEIM, Hermann: Trattato di Criminologia comparata, $2^{\mathrm{a}}$ Edición. Giulio Einaudi editore, editado por Franco Ferracuti, Torino, 1975. p. 15.

48 MAROTTA, Gemma: Criminologia, storia, teorie, metodi, Wolters Kluwer, Vicenza, seconda edizione, 2017. p. 2.

49 GARCÍA PABLOS, Antonio, op. cit., p. 4.

50 MANNHEIM, Hermann, op. cit., p. 15.

51 SERRANO MAÍlLO, Alfonso, op. cit., p. 532. 
probabilidad de ocurrencia de resultados. También se ha distinguido entre los conceptos de correlación y causa. ${ }^{52}$

Representando esta tendencia predominante en España y Latinoamérica, Rivacoba sostuvo que los factores permitían superar el concepto de causa. ${ }^{53}$ En un sentido similar Serrano propuso realizar investigaciones basadas en elementos concurrentes, reconociendo que, en estos fenómenos, en especial el estudio del delincuente, concurren una serie de antecedentes que influyen en su comportamiento, los que, seguramente, tendrán un distinto valor de incidencia en el resultado. ${ }^{54}$

Por ello, se puede decir que un evento tiene varias causas con distinta proximidad al resultado final. En consecuencia, parece que la existencia de una relación causal se refiere a una probabilidad más que a una certeza. ${ }^{55}$ Este asunto es relevante al momento de intentar realizar una interpretación con información criminológica, ya que no se pretende arribar a conclusiones en términos absolutos, sino que debe operar como ilustración del hecho.

Otro asunto relevante dice relación con el carácter interdisciplinario o multidisciplinario de los estudios criminológicos. Para algunos especialistas la Criminología es una disciplina muy desordenada, ${ }^{56}$ pues en sus investigaciones intervienen distintas ciencias. Sin embargo, otros estiman que justamente ahí radica la principal fortaleza. ${ }^{57}$

La mayoría de los manuales de Criminología explican que en su interior confluyen análisis sobre el fenómeno criminal desarrollados por la Biología, Psicología, Sociología,${ }^{58}$ Historia, Política, Economía, Geografía, Derecho, Antropología ${ }^{59}$ y las Ciencias médicas. ${ }^{60}$

Esta idea no debe hacer creer que el criminólogo es un experto en cada una de estas disciplinas. ${ }^{61}$ Por el contrario, los aportes de cada especialidad

52 Es decir, estas investigaciones aspiran a identificar factores relevantes en la concurrencia de los hechos estudiado. En ese sentido: LARRAURI, Elena, op. cit., p. 139.

53 RIVACOBA Y RIVACOBA, Manuel: Elementos de Criminología, Edeval, Valparaíso, 1982: p. 71.

54 SERRANO MAÍlLO, Alfonso, op. cit., p. 218.

55 JONES, Stephen, op. cit., p. 7.

56 BOSWORTH, Mary, HOYLE, Carolyn: "What is Criminology? an Introduction". En: What is Criminology, First Edition, Oxford University Press, Oxford, 2011. pp. 8 y 9.

57 NEWBURN, Tim, op. cit., p. 5.

58 MANNHEIM, Hermann, op. cit., p. 23.

59 CASE, Steve, op. cit., p. 34.

60 BOSWORTH, Mary, HOYLE, Carolyn, op. cit., p. 9.

61 SEELIG, Ernesto: Tratado de Criminología, Instituto de Estudios Políticos, Madrid, 1958 (traducción de José María Rodríguez Devesa), 1958. p. 6. 
confluyen en la producción del conocimiento y, con ello, se propende a superar una dificultad metodológica fuerte, fundada en el excesivo encasillamiento entre el trabajo cualitativo y cuantitativo. ${ }^{62}$ Además, esta forma de trabajar permite prevenir la subordinación disciplinar y las conclusiones contradictorias respecto del fenómeno estudiado. ${ }^{63}$ En consecuencia, tal como señaló Manheimm, la Criminología se convirtió en un terreno neutral para discutir. ${ }^{64}$

Ahora bien, cómo la Criminología consigue superar estas dificultades es un asunto que sigue cuestionándose. Tal como constató Agüero, en su interior algunos autores sostienen que se trabaja mediante un sistema multidisciplinario o interdisciplinario, e incluso algunos son partidarios de que ambos conviven simultáneamente. ${ }^{65}$

\section{LAS VINCULACIONES ENTRE LA CRIMINOLOGÍA Y EL DERECHO PUNITIVO.}

Ya se ha explicado que las relaciones con las ciencias sociales son fundamentales en el estudio del fenómeno criminal, pues todas estudian el mismo fenómeno humano, revisando su dimensión social y antropológica ${ }^{66}$ Dentro de las vinculaciones más importantes y complejas se destaca la relación con el derecho punitivo. En particular, se sostendrá que la legislación punitiva y la dogmática penal aportan en la configuración de la Criminología y esta última contribuye a delimitar los textos jurídico penales y su interpretación.

Una premisa básica que se debe recordar la formuló Seelig, al afirmar que "cada una de esas dos ciencias, desde el punto de vista teorético gnoseológico es igualmente necesaria y trae su legitimación de su propio valor gnoseológico y no, por ejemplo, de la ayuda que presta a la disciplina hermana". ${ }^{67} \mathrm{Ambas}$ disciplinas pueden revisar las investigaciones de la otra para estudiar sus aportes.

62 BOTTOMS, Anthony: "The relationship between theory and empirical observation en criminology". En: Doing research on crime and justice, Second Edition. Oxford University Press, Oxford, 2008. pp. 79-80.

63 RIVACOBA Y RIVACOBA, Manuel, Elementos de Criminología, op. cit., p. 78.

64 MANHEIMM, Hermann, op. cit., p. 23.

65 AGÜERO SAN JUAN, Sebastián, op. cit., p. 54.

66 PONTI, Gian Luigi: Compendio di Criminologia, Librería Cortina, Milano, 1980. p. 5.

67 SEELIG, Ernesto, op. cit., p. 26. 
En resumen, tienen una relación peculiar, pues la Criminología puede ir moldeando el contenido del texto legal punitivo y, a su vez, los tipos penales marcarán los contornos de las investigaciones criminológicas. Sin perjuicio de ello, existen diferencias metodológicas en el trabajo de cada investigación, las que serán abordadas en la medida que se desarrollen estas reflexiones.

Las primeras disputas fueron consecuencia de las concepciones vigentes en la época del siglo XIX. Durante esos años la ciencia jurídico-penal realizaba sus análisis en un plano teórico, asumiendo un estudio totalmente abstracto del contenido de las leyes, destinando esfuerzos a fundamentar el ius puniendi a precisar el fin de las penas y la responsabilidad criminal. En definitiva, sus aportes reflejaban un trabajo de especulación filosófica.

Este panorama tuvo un vuelco con la influencia del método de las ciencias naturales. Comenzaron a desarrollarse estudios sobre el delito fundado en dicha metodología, concibiéndolo básicamente como un fenómeno natural y social. Ese paradigma influyó fuertemente, y por años, en Italia e Iberoamérica, siendo resistido en el pensamiento alemán; ${ }^{68}$ consecuentemente, el Derecho penal quedó desplazado y reducido por la investigación criminológica. De ahí se pueden comprender las razones por las que algunos autores sostuvieron radicalmente que la Criminología era una meta-ciencia del Derecho criminal, ${ }^{69}$ e incluso las afirmaciones que negaban la ideología jurídico-penal. ${ }^{70}$

A lo largo de la compleja relación entre dogmática penal y Criminología se ha reconocido su autonomía, pero con una fuerte vinculación, ya que ambas se desempeñan como auxiliares de la otra, y si bien observan el fenómeno delictivo, tienen objetos de estudios distintos. La ciencia jurídico penal estudia "la ley positiva jurídico-penal; esto es determinar cuál es el contenido del Derecho penal, qué es lo que dice el Derecho penal". ${ }^{71}$ Por otro lado, la Criminología apunta a establecer causas o factores que confluyen en la comisión del delito.

A pesar de las diferencias descritas anteriormente, desde la obra de Von Liszt se sostuvo que era necesario establecer una relación de

68 RIVACOBA Y RIVACOBA, Manuel, Elementos de Criminología, op cit., pp. 38 y 39.

69 MANNHEIM, Hermann, op. cit., p. 23.

70 BARATTA, Alessandro: "Criminología y Dogmática Penal. Pasado y futuro del modelo integral de la ciencia penal”. En: Revista de Sociología, volumen 13, Barcelona, 1980. p. 27.

71 GIMBERNAT ORDEIG, Enrique: Concepto y método de la ciencia del Derecho penal, Tecnos, Madrid, 1999. p. 36. 
interdependencia entre ambas. En este sentido, concluyó que "sólo la reunión de los dos métodos, recíprocamente examinados y completados por el otro permiten conducir a un conocimiento exacto del crimen". Entonces, es perfectamente posible que un mismo hecho sea analizado mediante criterios normativos, valorativos, finalistas o a través cualquier otra clase de estudios, y eso no lo hará perder su unidad. ${ }^{72}$

En la actualidad una tendencia amplia al interior de la doctrina penal propone desarrollar una relación equilibrada entre ambas, ${ }^{73}$ sin intentar dirigir la evolución de la otra, ${ }^{74}$ es decir, deben trabajar como ciencias asociadas. La visión de Rivacoba reflejó este espíritu, entendiendo que el trabajo de los jueces en la construcción de las argumentaciones de sus sentencias, exige elaborar razonamientos de carácter lógico y expresando conocimientos sobre los datos de la criminalidad y juicios valorativos. ${ }^{75}$

\section{Primera vinculación: configuración recíproca del objeto de estudio.}

Una primera conexión epistemológica viene dada porque la Criminología y la Dogmática penal observan el mismo fenómeno, utilizando distintas metodologías. Tal como señaló Zaffaroni, existe una superposición en el objeto de estudio entre ambas. ${ }^{76}$ Estos acontecimientos se pueden estudiar como un fenómeno social llamado criminalidad o como hecho individual denominado delito. ${ }^{77}$

Precisamente la definición del delito como objeto de estudio de la Criminología ha dado lugar a un interesante debate, siendo el "más difícil que deba afrontar y también sus consecuencias son las más decisivas". ${ }^{78}$ Concretamente se ha discutido la posibilidad de adoptar un concepto legal,

72 VON LISZT, Franz: Tratado de Derecho penal, volumen 2. Hijos de Reus, Madrid, España (traducción de Luis Jiménez de Asúa y adiciones de Quintiliano Saldaña), 1916. p. 9.

73 MAURACH, Reinhart: Tratado de Derecho penal, Ediciones Ariel, Barcelona, (traducción de Juan Córdoba Roda), 1962. p. 47.

74 SERRANO GÓMEZ, Alfonso: "La criminología crítica". En: Anuario de Derecho penal y ciencias penales, en Tomo 36, número 1983. p. 53.

75 RIVACOBA Y RIVACOBA, Manuel: “Criminología y Sistema penal”. En: Gaceta jurídica, número 108, 1989. pp. 6-8.

76 ZAFFARONI, Eugenio R, op. cit., p. 123.

77 HASSEMER, Winfried y MUÑOZ CONDE, Francisco: Introducción a la Criminología y al Derecho penal, Tirant lo Blanch, Valencia, 1989. p. 27.

78 SERRANO MAÍlLO, Alfonso, op. cit., p. 68. 
obtenido a partir de los elementos que entrega la legislación, o bien uno natural, incluso la instauración de otro criminológico.

Tal como señalaba Pavarini, si el Derecho penal dota de objeto a la Criminología produce una doble reducción en el objeto, limitando sus posibilidades de conocimiento, porque sólo analizará lo que la legislación criminal defina como delito, y termina estudiando aquello que es efectivamente perseguido por los aparatos de control social, es decir, los crímenes en que sus autores son derivados a la cárcel, manicomio o las oficinas policiales. ${ }^{79}$ Consecuentemente, se buscaba avanzar en una ciencia criminológica que se mantuviera alejada de políticos, legisladores y abogados.

Como contrapartida, otros autores consideraron que debe emplearse el concepto de delito consagrado en la ley ${ }^{80}$ es decir, necesita acotarse a las conductas tipificadas como tal en la legislación criminal.

Un matiz en el debate introdujo Rivacoba al concluir que se debe seguir el concepto legal, suprimiendo las referencias a valores, manteniendo solamente los aspectos del fenómeno natural que permitirán pesquisar las causas individuales o sociales de su comisión. ${ }^{81}$ En este sentido, numerosos criminólogos han propuesto tener en cuenta los elementos del delito según los textos legales, pero complejizando su estudio, reconociendo que la noción legal de delito no coincide con las categorías criminológicas. ${ }^{82}$

Además del control social formal, se debe analizar la interacción entre el autor del delito, la víctima y el objeto del delito, con el control social informal. En palabras sencillas, se ha propuesto ampliar el objeto de estudio revisando el comportamiento antisocial, incluyendo las denominadas las conductas desviadas que son atípicas, jurídicamente hablando, ${ }^{83} \mathrm{o}$ incluso la reacción de la sociedad hacia el crimen, prescindiendo de la definición legal. ${ }^{84}$ Entonces, como la Criminología estudia el proceso de criminalización, analiza no solo los comportamientos tipificados, sino que todas aquellas que rodean el fenómeno delictivo.

79 PAVARINI, Massimo: Control y dominación: Teorías criminológicas burguesas y

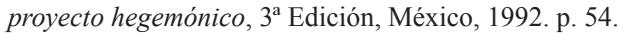

80 PONTI, Gian Luigi, op. cit., p. 29.

81 RIVACOBA Y RIVACOBA, Elementos de Criminología, op. cit., p. 73.

82 LARRAURI, Elena, op. cit., p. 17.

83 GARRIDO GENOVÉS, Vicente: Manual de criminología aplicada, Cuyo, Mendoza, 1997. p. 119.

84 MANNHEIM, Hermann, op. cit., pp. 19-20. 
En síntesis, los estudios criminológicos revisarán textos legales, sentencias judiciales y el trabajo de la dogmática penal, para marcar los contornos de su propia investigación. En algunos casos se ceñirá estrictamente a aquellas conductas tipificadas como delitos en la ley penal, pero también seleccionará comportamientos y factores que no pueden ser calificados como tales, pero que son sumamente relevantes en el estudio de la criminalidad, por ejemplo, las primeras conductas antisociales del autor, antecedentes facilitadores de la comisión de delitos, la influencia de los controles sociales formales e informales y la reacción social.

Desde la perspectiva jurídica, los estudios sobre la realidad criminal influyen en el establecimiento de leyes penales, siendo esta una de las vinculaciones más aceptadas en la dogmática penal y las investigaciones criminológicas. En un plano ideal, Díez Ripollés nos recuerda que criminólogos y otros especialistas debieran concurrir con planes de acción respecto del fenómeno de la delincuencia, proponiendo soluciones técnicas al respecto, basadas en el conocimiento especializado que detentan, sus equipos de estudio y medios técnicos para investigar; sin embargo, en la realidad terminan defendiendo diversos intereses ideológicos, socioeconómicos o puramente científicos. Sus propuestas pueden oírse a nivel pre- legislativo o en las comisiones técnicas de los parlamentos, es común que termine predominando una desconsideración de la pericia como rasgo característico de la actual política legislativa, principalmente en materia penal. ${ }^{85}$

En consecuencia, en la práctica en muchas ocasiones se desconoce la información criminológica, anulado la pretensión de la Criminología en orden a influir en la generación de políticas públicas y en la configuración del contenido de las leyes penales. Si bien es cierto, muchos de sus estudios adoptan el método científico y un lenguaje cercano a las ciencias naturales para influir en las instituciones de toma de decisiones, finalmente terminan recibiendo fuertes críticas por el excesivo interés en ser oído, obtener reconocimiento y legitimación de las autoridades, en vez de cuestionar el funcionamiento del sistema punitivo ${ }^{86}$

85 DÍEZ RIPOLLÉS, José Luis: La racionalidad de las leyes penales, Trotta, Madrid (segunda edición), 2013. pp. 30-31.

86 HOPE, Tim: "Official Criminology and the new crime sciences". En: What is Criminology, Oxford University Press, Oxford, 2011. p. 466. 


\section{Segunda vinculación: el estudio del control social formal.}

Desde el desarrollo de la teoría del Labeling approach en los años sesenta se ha reconocido la relevancia los controles sociales en el fenómeno criminal. En palabras sencillas, todas las sociedades necesitan de ciertos mecanismos internos que garanticen la cohesión social. Para ello despliegan una serie de procesos o instrumentos que aseguran el cumplimiento de las pautas de conducta, es decir, los controles sociales. Estos comprenden un "conjunto de instituciones, estrategias y sanciones sociales que pretenden promover y garantizar dicho sometimiento del individuo a los modelos y normas comunitarias". ${ }^{87}$ Ellos pueden ser controles sociales informales o formales. ${ }^{88}$ De ahí que los mecanismos formalizados solamente operan cuando los controles informales no consiguieron que el individuo adaptara su conducta a las pautas de comportamiento mayormente aceptadas. ${ }^{89}$ Por su intensidad, los controles formales están regulados legalmente, precisando los organismos y sanciones que se utilizarán..$^{90}$

El estudio de la influencia de los controles sociales en la configuración de la criminalidad, exige que la comprensión de la delincuencia analice el funcionamiento del sistema punitivo. El contenido y ejercicio del ius puniendi no es neutral y podrá traer consecuencias en la comisión de delitos, ya que "el sistema penal, por tanto, no responde a un delito, sino que cuando reacciona frente a un comportamiento, contribuye a que sea definido como delito". De esta forma, se podrá estudiar la regulación de las normas jurídicas y su aplicación institucional. ${ }^{91}$

Para ello se estudiará la actuación de las fuerzas policiales, la labor de jueces y fiscales y las penas impuestas, ${ }^{92}$ analizando cómo estas personas $\mathrm{y}$ organizaciones trabajan juntos o no, integrando un sistema complejo que responde al fenómeno criminal. Incluso algunos estudios se han incorporado a las víctimas afectadas por los crímenes. Las investigaciones

87 GARCÍA PABLOS, Antonio, op. cit., p. 148.

88 A partir de lo anterior se reconocen dos tipos de control, el informal y el formal. El primero de ellos comprende entidades como la familia, religión, escuela, profesión y la opinión pública; mientras que los segundos son conformados por instituciones que funcionan ejerciendo mecanismos coercitivos, más intensos, respecto de conductas alejadas de las normas sociales, los que se aplican por el control social penal. Ambos intervienen conjuntamente para contribuir a la prevención de los delitos. En ese sentido: GARRIDO GENOVÉS, Vicente, REDONDO ILLESCAS, Santiago, op. cit., p. 69.

89 GARCÍA PABLOS, Antonio, op. cit., pp., 148-150.

90 GARRIDO GENOVÉS, Vicente, REDONDO ILLESCAS, Santiago, op. cit. p. 69.

91 LARRAURI, Elena, op. cit., p. 19.

92 Ibídem, pp. 20- 22. 
también pueden comprender los efectos disuasorios de la vigilancia, tasas de esclarecimientos de delitos, efectos preventivos de las penas, entre otros. ${ }^{93}$

Precisamente, uno de los caminos seguidos por los criminólogos consiste en estudiar los procesos de criminalización, pues permite precisar con mayor claridad las vinculaciones entre ley penal y sistema de justicia criminal. ${ }^{94}$ También se analizan los resultados de la criminalización, revisando las consecuencias del proceso de reforma legal, judicial (incorporando el rol del Ministerio Público) y otros procedimientos penales. Además, puede examinarse la práctica criminalizadora comprensiva de la creación, interpretación y aplicación de los órganos que componen el sistema criminal, incluyendo policías, fiscales, jueces, abogados y el público. ${ }^{95}$

Desde la perspectiva jurídica algunas voces han propuesto estudiar el proceso de legitimación de las leyes punitivas revisando empíricamente cómo se aplican. Un ejemplo de esta propuesta la desarrolló Fernández al sostener que la delincuencia y los medios de control, constituyen posibles objetos de estudio del análisis crítico del discurso, al contener aspectos sumamente conflictivos por reproducir el control y la desigualdad social. ${ }^{96}$

Ello debe motivar a los investigadores a analizar el discurso utilizado en instituciones públicas, puesto que "la realidad social está limitada y construida por la realidad colectiva del lenguaje". ${ }^{97}$ Por lo tanto, si bien se ha hecho un estudio extenso del lenguaje empleado en los medios de comunicación masivos, también sería posible extenderlo a los textos legales en materia penal. Dicha tarea exige desarrollar un trabajo enmarcado en la denominada Criminología posmoderna, entendida como extensión de la Criminología crítica, que revisa los micro procesos del poder penal y el discurso utilizado en las relaciones de poder, "así, por ejemplo, el discurso de un policía reflejará lo que supone debe ser un policía, es decir, asumirá la posición del discurso policial dominante". Su premisa de trabajo asume

93 GARRIDO GENOVÉS, Vicente, REDONDO ILLESCAS, Santiago, op. cit., p. 70. Todo ello permite concluir que la ciencia integrada del Derecho penal debe emplear una interdisciplinariedad interna, para que todas las disciplinas se centren en un objeto único. En ese sentido: BARATTA, Alessandro, Criminología y sistema penal, op.cit., p. 168.

94 LACEY, Nicola, ZEDNER, Lucia: "Criminalization: Historical, legal, and criminological perspectives". En: The oxford handbook of Criminology, Alison Liebling, Shadd Maruna y Lesley McAra (eds.), Oxford University Press, Oxford, 2012. p. 57.

95 LACEY, Nicola, ZEDNER, Lucia, op. cit., p. 59.

96 FERNÁNDEZ CRUZ, José Ángel: “Análisis crítico del discurso y criminología. Una aproximación interdisciplinar”. En: Política Criminal, volumen 8, número 16, 2013. p. 496.

97 Ibídem., p. 481. 
que el delito es resultado de una producción lingüística expresiva de relaciones de control y poder, por lo que la delincuencia se configura a partir del discurso dominante. ${ }^{98}$

Entonces, si se analiza el lenguaje empleado por los funcionarios policiales ¿no debería dedicarse esfuerzos al examen del lenguaje de las leyes penales y de las sentencias dictadas por los jueces, en la medida que ambos contribuyen a definir el control social? Parece ser que esa vía es un camino que podrá recorrerse tanto por la Criminología como por aquellos especialistas dedicados al análisis de discursos en el derecho punitivo.

La segunda posibilidad es que la propia dogmática penal cumpla una de las principales funciones que se les ha asignado, consistente en "controlar críticamente la racionalidad de las decisiones adoptadas en el ejercicio del poder punitivo estatal". ${ }^{99}$ Una opción teórica ha sido desarrollada a partir la teoría de la argumentación jurídica, propone analizar diversos niveles racionalidad de las leyes penales siguiendo un modelo construido para estos fines.

Al efecto, Díez Ripollés propone una adaptación del esquema de Atienza, enfocándolo únicamente en la legislación punitiva. Para ello asume que existen distintas racionalidades, compuestas por la racionalidad ética, teleológica, lingüística, jurídico formal, pragmática y teleológica. Todas deben funcionar de forma integrada la configuración la ley. Concretamente, "la racionalidad ética marcaría el ámbito de juego de las restantes racionalidades, la teleológica establecería los objetivos a satisfacer dentro de ese marco, y las restantes se suceden en un orden de proyección decreciente de instrumentalidad". ${ }^{100}$

Por lo tanto, si un estudioso del Derecho penal o un criminólogo analiza la racionalidad de las leyes punitivas deberá converger en el análisis del cumplimiento de los estándares de la racionalidad pragmática. La irracionalidad en ese ámbito se verificará cuando estemos frente a "leyes penales que no son susceptibles de un apreciable cumplimiento por los ciudadanos o de una significativa aplicación por los órganos de control social jurídico sancionador, cuanto ante leyes que, en cualquier caso, no logran los objetivos pretendidos". ${ }^{101}$

98 Ibíd., p. 482.

99 SCHURMANN OPAZO, Miguel, op. cit., p. 555.

100 DÍEZ RIPOLLÉS, José Luis, La racionalidad de las leyes penales, 2013, pp. 90-96.

101 Ibíd., pp. 90-96. 


\section{Tercera vinculación: analizan el mismo objeto, pero empleando métodos diferentes.}

Como ya se ha afirmado la Criminología y la dogmática penal estudian el mismo objeto; sin embargo, la metodología que emplea cada una es diferente y ello no debería representar una sorpresa. En la tradición europea-continental, que ha predominado en nuestra región, y en el modelo anglosajón, estas disciplinas interactúan constantemente. Esto ha traído como consecuencia que "las tradicionales diferencias metodológicas han generado un oscurecimiento en el estudio del hecho que la elaboración, interpretación y aplicación del Derecho penal ocurre en un contexto social $\mathrm{y}$, por lo tanto, no se ha puesto más atención a los procesos políticos que conllevan". ${ }^{102}$

Sin embargo, el hecho de compartir el objeto de estudio contribuye a generar distintas maneras de interpretar la realidad social y ofrecer mecanismos variados para disminuir la comisión de delitos. ${ }^{103}$

El trabajo criminológico desarrollado a partir de la aplicación del método científico ha resultado especialmente prolífico para comprender el fenómeno criminal, es decir, analiza aspectos empíricos, mirados desde una perspectiva cercana a la explicación causal, o en términos más honestos intelectualmente, detectando los factores que inciden en su comisión. ${ }^{104}$

Cuando se hace referencia al carácter marcadamente empírico de la Criminología, se intenta resaltar su objeto de análisis integrante del denominado mundo real, pues busca conocer la realidad. Los estudios sobre delito, delincuente, víctima y control social contarían con un substrato real, no condicionado por aspectos valóricos. Tal como señala García Pablos, se trataría de un hecho más. En consecuencia, mediante un procedimiento inductivo se analizan los datos y comprueba las hipótesis, alejándose de argumentos de autoridad o consideraciones subjetivas. ${ }^{105}$

102 LACEY, Nicola, ZEDNER, Lucia, op. cit., p. 58.

103 Un ejemplo de lo anterior son los estudios sobre mujeres privadas de libertad. En estos casos los análisis de la Dogmática jurídico-penal revisarán la legislación aplicable, reglamentos y toda clase de instrumentos normativos que regulen su situación; por el contrario, la investigación criminológica aplicará probablemente metodologías cuantitativas y cualitativas que permitan desarrollar entrevistas a las mujeres encarceladas y sus familias, sumado la revisión de expedientes y otros documentos penitenciario. En ese sentido: GARRIDO GENOVÉS, Vicente, REDONDO ILLESCAS, Santiago, op. cit., p. 131.

104 PONTI, Gian Luigi, op. cit., p. 8.

105 GARCÍA PABLOS, Antonio, op. cit., pp. 5 y 6. 
Desde la otra vereda, tradicionalmente se ha afirmado que la ciencia jurídico-penal, en su afán de conocer, explicar y sistematizar el derecho punitivo, valora, ordena y orienta su contenido de acuerdo con criterios axiológicos. Para ello emplea un razonamiento deductivo, de carácter dogmático, a diferencia de la Criminología, que realiza su labor mediante un razonamiento de tipo inductivo e interdisciplinario, en búsqueda de posibles causas o factores que expliquen el fenómeno de la criminalidad.

El trabajo de los juristas dedicados al estudio del derecho criminal se vincula a procedimientos deductivos, pero también en algunos casos hermenéuticos, buscando fijar el significado de los enunciados normativos. ${ }^{106}$ Para otros especialistas, la labor de la dogmática penal se enfoca en la construcción de premisas que permitan deducir consecuencias jurídicas correctas. ${ }^{107}$ También algunas voces demandan que el trabajo dogmático reconstruya racionalmente todo el sistema jurídico. Sumado a la propuesta de que esta ciencia debería precisar el Derecho penal legítimo $\mathrm{y}$ vigente en la sociedad. Todo ello sin perjuicio de las otras posturas que se explicaron con mayor detalle en las páginas anteriores.

Mirando un poco más profundamente el problema, si se examina el trabajo mismo desarrollado por la Dogmática penal, Pulitanò nos recuerda que en realidad analiza el lenguaje de las normas contenidas en el ordenamiento jurídico. Por lo tanto, este lenguaje "lo construye la ciencia, a partir del lenguaje común y del lenguaje legislativo". Sus conclusiones persiguen interpretar dichos textos y desarrollar propuestas teóricas de naturaleza distinta a la interpretativa. Igualmente reconoce que su objeto no se reduciría sencillamente a los cuerpos legales, sino que también los procesos de formación, comprensión y aplicación del ordenamiento jurídico-penal. ${ }^{108}$ Esto es relevante, pues el análisis de la jurisprudencia normalmente integra los estudios de esta disciplina y, tal como señaló Gimbernat, su utilidad radica en facilitar la tarea de resolución de casos para el juez, por lo que se contribuye a un diálogo entre ambos sectores. ${ }^{109}$

Por supuesto, estas diferencias metodológicas obedecen a que ambas disciplinas persiguen fines diversos y realizan razonamientos distintos, aunque compartan el objeto de estudio. Tal como señalan Garrido y

106 GENOVÉS, Vicente, REDONDO ILLESCAS, Santiago, op. cit., p. 131.

107 GARCÍA PABLOS, Antonio, op. cit., p. 6.

108 PULITANÒ, Doménico: "Il diritto penale tra vincoli di realtà e sapere scientifico". En: Rivista italiana di diritto e procedura penale, número 49, 2006. pp. 852- 855.

109 GIMBERNAT ORDEIG, Enrique, op. cit., p. 123. 
Redondo, los resultados de estas investigaciones generan distintas interpretaciones del mismo fenómeno. Por un lado, los juristas modelan sus respuestas respetando normas y valoraciones, mientras que los criminólogos fundan sus conclusiones en aspectos empíricos fijados por la investigación científica. ${ }^{110}$ El Derecho penal y sus estudiosos seleccionan la realidad que analizarán a partir de criterios de la fragmentariedad propia de la legislación punitiva, tanto en disposiciones de la Parte especial como de la Parte general. Por otro lado, la Criminología selecciona los fenómenos que analiza conforme a investigaciones científicas. ${ }^{111}$ Ello se traduce, evidentemente, en soluciones disímiles para el problema criminal. ${ }^{112}$

Actualmente, Ferrajoli es partidario de refundar la Criminología crítica, ampliando nuevamente su objeto de estudio, para que la investigación criminológica se centre también en la criminalidad del poder, los crímenes de Estado y de sistema, desarrollando respuestas en los márgenes del Estado de Derecho y los principios garantistas. ${ }^{113}$ Para Del

110 GENOVÉS, Vicente, REDONDO ILLESCAS, Santiago, op. cit., p. 131.

111 GARCÍA PABLOS, Antonio, op. cit., p. 6.

112 Con todo, esta pretendida clara diferenciación ha sido cuestionada desde sus cimientos por los criminólogos críticos. Una prueba de esta controversia se vislumbra en el debate público protagonizado en Latinoamérica por Lola Aniyar de Castro, Eduardo Novoa Monreal y Roberto Bergalli. Esta discusión se inició por la afirmación que sostuvo el penalista chileno al argumentar en torno a una falta de orientación epistemológica de la Criminología crítica en relación al Derecho penal. A su parecer, esta situación habría surgido por la ampliación de su objeto de estudio a todas las formas de control social. NOVOA MONREAL, Eduardo: “¿Desorientación epistemológica en la criminología crítica?". En: Doctrina Penal, año 8, número 30, Buenos Aires, 1985. p. 27. Así abandonó la posición histórica de que la Criminología estudiaba las causas o factores del delito. Dicho ensanchamiento no habría fijado con la adecuada precisión los límites entre varias ciencias sociales. NOVOA MONREAL, Eduardo: "Lo que hay al lado no es un jardín: mi réplica a L. Aniyar". En: Doctrina Penal, número 33/34, Buenos Aires, 1986. p. 51. En respuesta a la crítica, Aniyar argumentó que no existe una confusión de márgenes entre las disciplinas, a raíz de la indispensable colaboración interdisciplinaria, que debe vincular la tarea científica con la política. ANIYAR DE CASTRO, Lola: "El jardín de al lado, o respondiendo a Novoa sobre la Criminología Crítica”. En: Doctrina Penal, Depalma, Buenos Aires, número 33, 1986. pp. 40-44. Si bien el debate es mucho más extenso, Bergalli cerró la discusión al proponer separar la Criminología del conocimiento del control social, el que debía ser desarrollado mediante un pensamiento crítico latinoamericano para que la Dogmática penal se nutriera de la reflexión proveniente del análisis extra-normativo de la sociología del control penal. BERGALLI, Roberto: "Una intervención equidistante, pero en favor de la sociología del control penal”. En: Doctrina penal, Depalma, Buenos Aires, número 36, 1986. p. 69.

113 FERRAJOLI, Luigi: "Criminología, crímenes globales y derecho penal: el debate epistemológico en la criminología contemporánea". En: Crítica penal y poder, número 4, Barcelona, 2013. pp. 4 y 5. 
Olmo, en nuestro contexto social de predominante vigilancia y control, la Criminología se debe integrar el saber y el poder como forma de superar la postmodernidad. ${ }^{114}$

\section{Cuarta vinculación: Teoría jurídica e información empírica.}

En un número amplio de tratados y manuales se suele afirmar que la Criminología es una ciencia del ser y el derecho una ciencia del deber ser, generando la impresión en el lector de que se trata de compartimentos más o menos separados, que operan bajo lógicas y razonamientos diferentes. Por ejemplo, García Pablos afirma que la Criminología se desempeña en las ciencias empíricas, porque estudia un sustrato de la realidad, que sería verificable y medible, no en el plano de los valores. ${ }^{115}$ Sin embargo, parece ser que en la propia investigación criminológica, a pesar de ser marcadamente empírica, la teoría tiene un papel predominante, por lo que no es tan sencillo formular una aseveración tan tajante. Además, se producen dificultades por la profundidad del tema, ya que plantear la relación de la teoría y los datos es difícil. ${ }^{116}$

Una primera premisa para conducir el tema supone asumir que no existen hechos neutrales. ${ }^{117}$ A partir de ello se ha afirmado que la información criminológica rotulada como dato, aparentemente objetivo, en realidad expresa nuestras concepciones teóricas y ellas influyen también en la selección del tema que el investigador decide analizar y la perspectiva que empleará en su trabajo. ${ }^{118}$

Incluso para algunos investigadores dedicados a la Criminología los datos o información en bruto no son deseados ni necesarios, llegando a ser irrelevantes. ${ }^{119} \mathrm{Tal}$ como recuerda Serrano "la ciencia no empieza por las observaciones ni por la acumulación de hechos. Pese a que es una concepción bastante extendida en la ciencia, ésta no consiste en reunir hechos particulares conocidos sobre una cuestión cualquiera como delito,

114 OLMO, Rosa del: "La criminología en la Cuarta Época: del saber al poder". En: Nova criminis: visiones criminológicas de la justicia penal, número 6, Centro de Investigaciones Criminológicas de la Justicia Penal de la Universidad Central, Santiago, 2013. p. 153 .

115 GARCÍA PABLOS, Antonio, op. cit., p. 5.

116 BOTTOMS, Anthony, op. cit., p.79.

117 Ibídem, p. 78.

118 LARRAURI, Elena, op. cit., p. 39.

119 BOSWORTH, Mary, HOYLE, Carolyn, op. cit., pp. 8 y 9. 
por ejemplo, para construir a partir de ellos -por inducción- una teoría general abstracta explicativa. Por el contrario, lo primero siempre es la teoría. Sin ella no es posible ni siquiera saber qué hechos particulares pueden ser relevantes y cuáles no". ${ }^{120}$

En segundo lugar, se podría reflexionar a propósito de la obtención y construcción de los datos. Su configuración expresa una selección de variables que, realmente, no son tan objetivas como aparentan. En ese sentido, Bottoms reconoce que la teoría está presente en su proceso de recopilación e interpretación, ${ }^{121}$ obviamente estos antecedentes fueron filtrados previamente aplicando una teoría. Tal como recuerda Larrauri, "por ejemplo, clasificamos en torno a variables como edad, género, inmigración (y no peso y optometría)". ${ }^{122}$

En tercer lugar, la relación de teoría y datos puede analizarse a partir de la valoración de la calidad de las teorías propuestas. Si se revisan los estándares generales, se entenderá adecuada una propuesta que tenga coherencia interna, un amplio ámbito de aplicación, contenido simple, previsible y con aplicaciones prácticas; reconociendo que es posible, no todas las investigaciones cumplen todos estos estándares. ${ }^{123}$

Ahora bien, Bottoms relató una experiencia personal profesional para ejemplificar este asunto y vale la pena revisarla. Cuando él se dedicó a hacer estudios penitenciarios, realizando una investigación en un centro de internación juvenil, recuerda haber asistido como observador a varias reuniones del personal, aburriéndose mientras se desarrollaban, ya que estaban dedicadas a estudiar, por ejemplo, los programas de tratamientos que ofrecían, los resultados de las intervenciones. Sin embargo, con el paso del tiempo entendió que la comprensión teórica de esta institución necesitaba considerar las rutinas diarias y sus detalles para conseguir mayor capacidad explicativa. ${ }^{124}$ En este caso, la teoría necesita de datos concretos, lo que nos conduce al siguiente tema a considerar.

El cuarto problema que se puede discutir se centra en la utilidad que tiene la relación entre datos y teorías. Concretamente, la revisión del trabajo desarrollado en investigaciones que persiguen explicaciones causales permite identificar que teoría y datos contribuyen a dar respuesta

120 SERRANO MAÍLLO, Alfonso, op. cit. pp. 41 y 42.

121 BOTTOMS, Anthony, op. cit., p. 78.

122 LARRAURI, Elena, op. cit., p. 39.

123 SERRANO MAÍlLO, Alfonso, op. cit., pp. 230-239.

124 BOTTOMS, Anthony, op. cit., p. 79. 
a la pregunta de investigación, recaída en el análisis de fenómenos sociales, es decir, persiguiendo "la verdad científica". Mientras en los análisis normativos, que buscan responder preguntas sobre la justicia y su aplicación, los datos ayudan a clarificar sus razonamientos y en análisis filosóficos complejos. ${ }^{125}$

Desde la perspectiva jurídico-penal, esta relación se expresa en los estudios teórico- científicos que analizan aspectos empíricos. Recordando lo señalado por Kindhäuser, la Dogmática penal debe comprender cabalmente los hechos naturales y sociales que regula el ordenamiento jurídico, ${ }^{126}$ es decir, debe conocer estos antecedentes empíricos para desarrollar el trabajo teórico legislativo. Por ello, sus conclusiones dependen parcialmente de categorías jurídicas y antecedentes de la realidad social "en tanto ella desea organizar el mundo según las valoraciones del derecho, solo puede recurrir a aquellos mecanismos que también pueden efectivamente condicionar cambios reales. En particular, ella no puede prescindir de conocimientos sobre el proceso causal". ${ }^{127}$

Su planteamiento nos conduce a una premisa fundamental: "El derecho es un orden de deber, es decir, con fundamento en el mundo natural produce un mundo institucional: El transforma hechos naturales en hechos institucionales". $\mathrm{Su}$ ejemplo sobre este asunto es bastante clarificador, pues recurre a la noción de culpabilidad, explicando que no se trata de una pretendida cualidad natural, como sería la composición de la sangre. Por el contrario, dicho concepto es normativo, supone un juicio de imputación compuesto por reglas jurídicas. Solamente así se determinará la capacidad de culpabilidad que permite a las personas actuar siguiendo los mandatos del Derecho. Por el contrario, "la adscripción de cualidades institucionales jurídico-penalmente relevantes es inútil cuando la afirmación de los correspondientes hechos primaros es falsa o, simplemente, su garantía es deficiente". ${ }^{128}$

\section{El uso de la información criminológica en la interpretación de las leyes penales.}

Como se dijo anteriormente la necesidad de regular aspectos de la realidad natural o social y la construcción de categorías teórico jurídicas referidas

125 Ibídem, pp. 105 y 106.

126 KINDHÄUSER, Urs, op. cit., p. 20.

127 Ibíd., p. 41.

128 KINDHÄUSER, Urs, op. cit., p. 40. 
a valores condicionan el trabajo de la ciencia jurídica, otorgándole elementos para seleccionar la obtención de datos empíricos concretos. Una manifestación de lo anterior se concreta en el uso de la información criminológica en el trabajo teórico de interpretación de las leyes punitivas.

En la dogmática jurídico-penal se distinguen varios antecedentes que motivan al penalista a adentrarse en el conocimiento criminológico. La primera sería una curiosidad natural por el objeto de estudio de su área de trabajo. Además, en bastantes casos, solamente se podrá arribar a precisar el significado del texto legal si se acude a la información aportada por la Criminología, es decir, se trata de razones de alto valor interpretativo. ${ }^{129}$

Como se ha dicho reiteradamente, la ciencia penal es una disciplina compleja, heterogénea, en que diversas escuelas son partidarias de una apertura epistemológica, que posibilita introducir antecedentes extrajurídicos en su argumentación teórica. Sin embargo, las reflexiones en este problema no son sencillas, sobre todo si se considera el discurso tradicional transmitido históricamente sobre elementos comunes $\mathrm{y}$ diferentes entre dogmática penal y Criminología. Afortunadamente el creciente reconocimiento de la vinculación entre teoría y datos, permite a juristas y criminólogos aceptar que esta tajante diferencia del plano del "ser" y el "deber ser" admite matices y cuestionamientos, y ellos no necesariamente nos conducirán al despeñadero de la falacia naturalista.

La clásica afirmación de que la Criminología es una disciplina alejada de valoraciones puede ser fuertemente criticada. Ella estudia el crimen, pero en su cometido termina revisando el contenido del derecho, con toda su carga valorativa y el sistema criminal que selecciona comportamientos desvalorados en la disposición jurídico-penal. ${ }^{130}$

Por una parte, si asumiéramos posiciones exclusivamente normativistas, probablemente caeríamos a un pantanoso y complejo escenario derivado de la excesiva abstracción teórica, desconectada de la realidad social. Este camino ya lo recorrió la ciencia jurídica en general y la dogmática penal, cuando predominaron tendencias como la jurisprudencia de los conceptos,

129 GIMBERNAT ORDEIG, Enrique, op. cit., p. 34.

130 "Un delito se determina no por caracteres reales del suceder, sino normativamente, por el ordenamiento jurídico respectivo". SEELIG, Ernesto, op. cit., p. 25. Precisamente la ciencia jurídica realiza reconstrucciones teóricas de segundo grado expresando la preformación conceptual de su materia, es decir, de antecedentes empíricos. RADBRUCH, Gustav: Tres estudios de Filosofia del Derecho y una arenga para los jóvenes juristas, B de F, Buenos Aires (traducción de José Luis Guzmán Dalbora), 2013. p. 40. 
que condujeron a que el péndulo se terminara trasladando al otro extremo, persistiendo hoy en las expresiones más extremas de funcionalismo. En consecuencia, una postura moderada que vincule ambos planos, puede contribuir a desarrollar análisis más completos e integrales para los juristas.

En el fondo, la interpretación de las leyes, sobre todo en casos difíciles, analiza algo que forma parte del mundo, integrando el contenido del sistema jurídico. Tal como señaló Zaffaroni toda labor hermenéutica requiere respetar su dimensión óntica. ${ }^{131}$

El proceso de determinación del contenido de la legislación criminal debe tener en cuenta las características de la realidad social que está regulando, sobre todo por razones de racionalidad legislativa. La historia nos recuerda que las categorías de las ofensas criminales son contingentes, no surgen de un plano abstracto o valorativo, desconectadas de la realidad, dependen de ciertos lugares y tiempos, recogiendo costumbres sociales, sensibilidades culturales, preceptos morales y religiosos. ${ }^{132}$

Por su parte, desde el ámbito criminológico, Herrero afirmó que esta disciplina proporciona al Derecho penal una base real, colmando de contenido "la letra y el espíritu de las normas", mientras que "corresponde a la Criminología inspirar, pero no determinar ni decidir". ${ }^{133}$ Constituye una base indispensable para la teoría y práctica del Derecho penal, penitenciario y procesal penal moderno.

En particular, respecto de la Criminología la situación es similar, ya que teóricamente, el sistema jurídico se construye a partir de la información que proporciona a la Política criminal. Tal como ha señalado recientemente Marotta, no se podría desconocer la contribución de la investigación criminológica en cada área del Derecho penal. ${ }^{134}$

131 En consecuencia, el trabajo dogmático necesita adentrarse en aquello regulado en las leyes. SAINZ CANTERO, José A.: La Ciencia del Derecho penal y su evolución, Bosch, Barcelona, 1970. p. 34. En palabras de Von Hentig "debemos recordar que en un plano ideal se ha señalado que una ley penal científica no sólo sería un sistema lógico altamente desarrollado, sino que reflejaría las normas de la Criminología más firmemente establecidas. Actualmente, aunque referidas a un fenómeno de la vida, llevan una existencia separada, representando dos sistemas algo celosos de conocimiento en la esfera de la ciencia". VON HENTIG, Hans: Criminología. Causas y condiciones del delito. Editorial Atalaya, Buenos Aires, (traducción de Diego Abad de Santillán), 1948. p. 29.

132 LACEY, Nicola, ZEDNER, Lucia, op. cit., p. 61.

133 HERRERO HERRERO, César: Criminología (Parte general y especial). Dykinson, Madrid, 2007. pp. 34-37.

134 MAROTTA, Gemma, op. cit., p. 32. 
En términos amplios, en la Parte general sería relevante la configuración de la culpabilidad, en la teoría de la pena, su ejecución, la aplicación de penas alternativas y de beneficios en el cumplimiento de la condena. ${ }^{135} \mathrm{~A}$ ello debe agregarse su conmensuración, la aplicación de las medidas de seguridad, el examen de imputabilidad, la valoración de la peligrosidad y de ciertas circunstancias. ${ }^{136}$

Respecto de la Parte especial, Gimbernat sostuvo más precisamente que la Criminología constituye una herramienta interpretativa útil tratándose del tipo de robo con violación y a propósito de problemas de autoría y participación en delitos terroristas $;^{137}$ mientras que Beristain agregó los tipos penales de auxilio al suicidio, aborto, rapto, crímenes de cuello blanco, ciertas acciones antirreligiosas y delitos políticos. ${ }^{138}$

\section{REFLEXIONES FINALES.}

Todo este recorrido teórico demuestra que es posible ampliar la forma tradicional de entender las vinculaciones entre Criminología y dogmática penal, morigerando la división tajante entre ser y deber ser, como también las propuestas que solamente reconocían una relación entre Criminología y Política criminal. Esta investigación fundamenta que es relevante valerse, en el proceso de interpretación de la ley penal, de los conocimientos criminológicos, para respetar la realidad óntica del fenómeno regulado.

Los argumentos que justifican dicha afirmación revisan el estatuto epistemológico de cada disciplina. En el fondo, se buscó distinguir más precisamente los contornos y características de ambas, precisar los métodos de trabajo y su susceptibilidad de recibir conocimientos provenientes de otras ciencias. ${ }^{139}$ A partir de ello se detectó una oportunidad adicional para utilizar la información criminológica en la interpretación legal.

Hoy resultaría arriesgado afirmar que estos antecedentes sobre la realidad social no son relevantes ni útiles para el Derecho penal y su interpretación. Estos conocimientos son ineludibles en el trabajo del intérprete, ya sea

135 PONTI, Gian Luigi, op. cit., p. 25 y HASSEMER, Winfried y MUÑOZ CONDE, Francisco, op. cit., p. 32.

136 MAROTTA, Gemma, op. cit., p. 32.

137 GIMBERNAT ORDEIG, Enrique, op. cit., p. 34.

138 BERISTAIN, Antonio: Ciencia penal y criminología, Tecnos, Madrid, 1985. p. 39.

139 RIVACOBA Y RIVACOBA, Manuel, Elementos de

Criminología, op. cit., págs. 28 y 29. 
porque constantemente surgen nuevas formas de criminalidad, ${ }^{140} \mathrm{o}$ bien porque en otras situaciones se enfrenta a casos difíciles cuya solución requiere incorporar elementos extrasistémicos que pueden hallarse en la investigación criminológica.

\section{BIBLIOGRAFÍA.}

AGÜERO SAN JUAN, Sebastián: "Apuntes sobre las dificultades en la determinación del estatus científico de la Criminología". En Revista Chilena de Derecho y Ciencia Política, Volumen 2, número 1, año 1, 2010.

ANIYAR DE CASTRO, Lola: "El jardín de al lado, o respondiendo a Novoa sobre la Criminología Crítica". En: Doctrina Penal, Depalma, Buenos Aires, número 33, 1986.

BARATTA, Alessandro: Criminología y sistema penal, B de F, Montevideo, 2006.

_ (1980) Criminología y Dogmática Penal. Pasado y futuro del modelo integral de la ciencia penal. En: Revista de Sociología, volumen 13, Barcelona.

BERGALLI, Roberto: "Una intervención equidistante, pero en favor de la sociología del control penal”. En: Doctrina penal, Depalma, Buenos Aires, número 36, 1986.

BOSWORTH, Mary, HOYLE, Carolyn: "What is Criminology? an Introduction". En: What is Criminology, First Edition, Oxford University Press, Oxford, 2011.

CASE, Steve, JOHNSON, Phil, MANLOW, David, SMITH, Roger, WILLIAMS, Kate: Criminology, Oxford University Press, Oxford, 2017.

140 Las conclusiones del autor italiano se desarrollan a partir del trabajo de la judicatura, pero la tarea interpretativa la realizan diversos actores, entre ellos la Dogmática penal y el legislador. Sus reglas metodológicas no cambian según el cargo que desempeña la persona que interpreta. Dicha característica permite extrapolar su propuesta a todo el quehacer hermenéutico jurídico-penal. FIANDACA, Giovanni: "Il giudice di fronte alle controversie tecnico-scientifiche. Il diritto e il processo penale". En: Pensare la complessità. Itinerari interdisciplinari, Sigma, Palermo, 2004. pp. 8- 10. 
CID, José, LARRAURI, Elena: Teorías criminológicas, Explicación y prevención de la delincuencia, Bosch, Barcelona, 2001.

BARATTA, Alessandro: Criminología y sistema penal, B de F, Montevideo, 2006.

- "Criminología y Dogmática Penal. Pasado y futuro del modelo integral de la ciencia penal". En: Revista de Sociología, volumen 13, Barcelona, 1980.

Introduzione alla Sociologia giuridico-penale. Criminologia critica e critica al diritto penale, Dispense del ciclo di lezioni tenute alla facoltà di Giurisprudenza dell'Università di Bologna, Bologna, 1980.

BERISTAIN, Antonio: Ciencia penal y criminología, Tecnos, Madrid, 1985.

BOSWORTH, Mary, HOYLE, Carolyn: "What is Criminology? an Introduction". En: What is Criminology, First Edition, Oxford University Press, Oxford, 2011.

DÍEZ RIPOLLÉS, José Luis: "El papel epistémico de la política criminal en las ciencias penales: la contribución de v. Liszt". En: Revista electrónica de Ciencia penal y Criminología, número 20, 2018.

_La racionalidad de las leyes penales, Trotta, Madrid (segunda edición), 2013.

DONINI, Massimo: "Democrazia e scienza penale nell'Italia di oggi: un rapporto possibile". En: Rivista italiana di diritto e procedura penale, volumen 53, número 3, 2010.

ESKRIDGE, Chris: "El estado actual de la Criminología". En: Revista Archivos de Criminología, Criminalística y Seguridad Privada, año 6, volumen XI, 2013.

FERNÁNDEZ CRUZ, José Ángel: “Análisis crítico del discurso y criminología. Una aproximación interdisciplinar". En: Política Criminal, volumen 8, número 16, 2013.

FERRAJOLI, Luigi: "Criminología, crímenes globales y derecho penal: el debate epistemológico en la criminología contemporánea". En: Crítica penal y poder, número 4, Barcelona, 2013. 
FIANDACA, Giovanni: "Il giudice di fronte alle controversie tecnicoscientifiche. Il diritto e il processo penale". En: Pensare la complessità. Itinerari interdisciplinari, Sigma, Palermo, 2004.

GARCÍAPABLOS DE MOLINA, Antonio: Criminología, una introducción a sus fundamentos teóricos, Lexis Nexis, Santiago, 2008.

GARRIDO GENOVÉS, VICENTE Y REDONDO Illescas, Santiago: Principios de Criminología, Tirant lo blanch, Valencia, 2013.

GARRIDO GENOVÉS, Vicente, Manual de criminología aplicada, Cuyo, Mendoza, 1997.

GIMBERNAT ORDEIG, Enrique: Concepto y método de la ciencia del Derecho penal, Tecnos, Madrid, 1999.

EUSEBI, LUCIANO: La pena “in castigo”, Vita e Pensiero, Milano, 2006.

JAKOBS, Günter: El Derecho penal como disciplina científica, Thomson, civitas, Pamplona, (traducción de Alex van Weezel), 2008.

HASSEMER, Winfried y MUÑOZ CONDE, Francisco: Introducción a la Criminología y al Derecho penal, Tirant lo Blanch, Valencia, 1989.

HERRERO HERRERO, César: Criminología (Parte general y especial), Dykinson, Madrid, 2007.

HOPE, Tim: "Official Criminology and the new crime sciences". En: What is Criminology, Oxford University Press, Oxford, 2011.

HRUSCHKA, Joachim: Imputación y Derecho penal, segunda edición, Buenos Aires (al cuidado de Pablo Sánchez Ostiz), 2009.

JIMÉNEZ DE ASÚA, Luis: Tratado de Derecho penal, Tomo I, Editorial Losada, Buenos Aires, 1964.

JONES, Stephen: Criminology, Oxford University Press, Oxford, 2009.

KINDHÄUSER, Urs: "Acerca del objeto y la tarea de la ciencia del Derecho penal". En: Derecho penal contemporáneo. Revista internacional, número 66, 2019.

LARRAURI, Elena: Introducción al sistema penal, Trotta, Madrid, 2015.

LACEY, Nicola, ZEDNER, Lucia: "Criminalization: Historical, legal, and criminological perspectives". En: The oxford handbook of Criminology, 
Alison Liebling, Shadd Maruna y Lesley McAra (eds.), Oxford University Press, Oxford, 2017.

MANNHEIM, Hermann: Tratato di Criminologia comparata, $2^{\text {a }}$ Edición, Giulio Einaudi editore, editado por Franco Ferracuti, Torino, 1975.

MAROTTA, Gemma: Criminologia, storia, teorie, metodi, Wolters Kluwer, Vicenza. Seconda edizione, 2017.

MAURACH, Reinhart: Tratado de Derecho penal, Ediciones Ariel, Barcelona, (traducción de Juan Córdoba Roda), 1962.

NEWBURN, Tim: Criminology, Tercera edición, Routledge, New York, 2017.

NOVOA MONREAL, Eduardo: “¿Desorientación epistemológica en la criminología crítica?”. En: Doctrina Penal, año 8, número 30, Buenos Aires, 1985

_ "Lo que hay al lado no es un jardín: mi réplica a L. Aniyar" en Doctrina Penal, número 33/34, Buenos Aires, 1986.

OLMO, Rosa del: "La criminología en la Cuarta Época: del saber al poder". En: Nova criminis: visiones criminológicas de la justicia penal, número 6, Centro de Investigaciones Criminológicas de la Justicia Penal de la Universidad Central, Santiago, 2013.

PAVARINI, Massimo, Control y dominación: Teorías criminológicas burguesas y proyecto hegemónico, $3^{\mathrm{a}}$ Edición, México, 1992.

PERIN, Andrea: "Conocimientos científicos, tecnologías convergentes y Derecho penal. Reflexiones metodológicas en materia de causalidad, imprudencia, imputabilidad y peligrosidad". En: Tecnologías convergentes: desafios éticos y jurídicos, Comares, Granada, 2016.

PONTI, Gian Luigi: Compendio di Criminologia, Librería Cortina, Milano, 1980.

PULITANÒ, Doménico: "Il diritto penale tra vincoli di realtà e sapere scientifico". En: Rivista italiana di diritto e procedura penale, número 49, 2006.

RADBRUCH, Gustav: Tres estudios de Filosofia del Derecho y una arenga para los jóvenes juristas, B de F, Buenos Aires (traducción de José Luis Guzmán Dalbora), 2013. 
RIVACOBA Y RIVACOBA, Manuel: Elementos de Criminología, Edeval, Valparaíso, 1982.

_ "Criminología y Sistema penal”. En: Gaceta jurídica, número 108, 1989.

SAINZ CANTERO, José: La Ciencia del Derecho penal y su evolución, Bosch, Barcelona, 1970.

SERRANO GÓMEZ, Alfonso: "La criminología crítica". En: Anuario de Derecho penal y ciencias penales, en Tomo 36, número 1, 1983.

SERRANO MAÍLLO, Alfonso: Introducción a la Criminología, UNED, Madrid, 2009.

SEELIG, Ernesto: Tratado de Criminología, Instituto de Estudios Políticos, Madrid, (traducción de José María Rodríguez Devesa), 1958.

SUTHERLAND, Edwin: Principles of Criminology, The United States Armed Forced Institute, Madison, 1939.

SCHURMANN, Miguel: “¿Es científico el discurso elaborado por la dogmática jurídica? Una defensa de la pretención de racionalidad del discurso dogmático elaborado por la ciencia del derecho penal". En: Política Criminal, volumen 14, número 27, 2019.

SILVA SÁNCHEZ, Jesús María: Aproximación al Derecho penal Contemporáneo, Editorial B de F, Buenos Aires, 2010.

VON HENTIG, Hans: Criminología. Causas y condiciones del delito, Editorial Atalaya, Buenos Aires, (traducción de Diego Abad de Santillán), 1948.

VON LISZT, Franz, Tratado de Derecho penal, volumen 2, Hijos de Reus, Madrid, España (traducción de Luis Jiménez de Asúa y adiciones de Quintiliano Saldaña), 1916.

VORMBAUM, Thomas: Historia moderna del Derecho penal alemán, Tirant lo Blanch, Valencia, (traducción de Carlos Elbert), 2018.

ZAFFARONI, Eugenio Raúl: Manual de Derecho penal, Parte general, Ediar, Buenos Aires, 2012. 